\title{
F-18 Fluoroethyltyrosine
}

National Cancer Institute

\section{Source}

National Cancer Institute. F-18 Fluoroethyltyrosine. NCI Thesaurus. Code C60818.

An amino acid analog radiolabeled with fluorine $F 18$, a positron emitting isotope, used as a tracer in positron emission tomography (PET). Reflecting the increased amino acid transport capacity of tumor cells, F-18 fluroethyltyrosine (F-18 FET) is actively taken up in tumor cells via the amino acid transport system, but is neither incorporated into proteins nor readily degraded, resulting in high intracellular concentrations of this imaging agent. Radiolabeled amino acid-based agents are useful in PET brain tumor imaging because F18 fluoro-deoxyg lucose (F-18 FDG), commonly used in PET tumor imaging, is relatively insensitive for detecting tumors in the brain due to high levels of glycolytic metabolism in the normal cortex and to a lesser extent in white matter. 